\title{
P02.112. Mind-body medicine therapies for the depression spectrum: a systematic review
}

\author{
S D'Silva ${ }^{1 *}$, C Poscablo' ${ }^{1}$ R Habousha², B Kligler ${ }^{3}$ \\ From International Research Congress on Integrative Medicine and Health 2012 \\ Portland, Oregon, USA. 15-18 May 2012
}

\section{Purpose}

This paper aims to systematically compare and contrast the evidence for the use of mind-body therapies to address varying degrees of depressive symptoms in populations with and without other chronic co-morbidities. Systematic literature searches of PubMed (Medline), Embase, CINAHL, and the 7 databases encompassed by Current Contents, Web of Science and Web of Knowledge were conducted from 1966 onward.

\section{Methods}

Studies had to be designed as prospective control-comparison, using a mind-body medicine modality at least 2 weeks long, in an adult population that speaks English, with a sample size $>30$, and with depression as a primary or secondary outcome measured on an established scale. Methodological quality was evaluated using the modified Scale for Assessing Scientific Quality of Investigations (SASQI) for Complementary and Alternative Medicine (CAM).

\section{Results}

Of the 2964 papers identified by database searches, 90 met our inclusion and exclusion criteria. Sixty percent of these papers received a SASQI score $>9$ and were deemed of sufficient quality to be included in the review. Seventy-two percent of these selected quality papers demonstrated positive effects on the improvement of depressive symptoms. Self-regulation (biofeedback, guided imagery and hypnosis) and interventions with mixed modalities had a higher proportion of positive results than movement (yoga, taichi and qigong) and mind-based (meditation and mindfulness) categories, although the latter two categories have been better studied.

${ }^{1}$ George Washington University, Washington D.C., USA

\section{Conclusion}

Along with established psychiatric treatments of therapy and medications for depression, the use of evidence-based mind-body therapies can provide further relief of symptoms in a patient-centered manner. The likely long-term increased cost-effectiveness of integrating these therapies deserves further investigation.

\section{Author details}

${ }^{1}$ George Washington University, Washington D.C., USA. ${ }^{2}$ Albert Einstein College of Medicine, Bronx, USA. ${ }^{3}$ Center for Health and Healing, Beth Israel Medical Center, New York City, USA.

Published: 12 June 2012

doi:10.1186/1472-6882-12-S1-P168

Cite this article as: D'Silva et al:: P02.112. Mind-body medicine therapies for the depression spectrum: a systematic review. BMC Complementary and Alternative Medicine 2012 12(Suppl 1):P168.
Submit your next manuscript to BioMed Central and take full advantage of:

- Convenient online submission

- Thorough peer review

- No space constraints or color figure charges

- Immediate publication on acceptance

- Inclusion in PubMed, CAS, Scopus and Google Scholar

- Research which is freely available for redistribution
() Biomed Central
Full list of author information is available at the end of the article

() Biomed Central 